\title{
Time course of temperature effects on cardiovascular mortality in Brisbane, Australia
}

\author{
Weiwei Yu, ${ }^{1}$ Wenbiao Hu, ${ }^{2}$ Kerrie Mengersen, ${ }^{3}$ Yuming Guo, ${ }^{1}$ Xiaochuan Pan, ${ }^{4}$ \\ Des Connell, ${ }^{5}$ Shilu Tong ${ }^{1}$
}

${ }^{1}$ School of Public Health and Institute of Health and Biomedical Innovation, Queensland University of Technology, Brisbane, Australia 2Department of Epidemiology, School of Population Health, University of Queensland, Brisbane, Australia ${ }^{3}$ Discipline of Mathematical Sciences, Faculty of Science and Technology, Queensland University of Technology, Brisbane, Australia ${ }^{4}$ Department of Occupationa and Environmental Health, School of Public Health, Peking University, Beijing, China ${ }^{5}$ Griffith School of Environment, Griffith University, Brisbane, Australia

\section{Correspondence to}

Weiwei Yu, School of Public Health and Institute of Health and Biomedical Innovation, Queensland University of Technology, Kelvin Grove, OLD 4059, Australia; weiwei.yu@qut.edu.au

Accepted 10 March 2011 Published Online First 12 April 2011

\section{ABSTRACT}

Objective To quantify the lagged effects of mean temperature on deaths from cardiovascular diseases in Brisbane, Australia.

Design Polynomial distributed lag models were used to assess the percentage increase in mortality up to 30 days associated with an increase (or decrease) of $1^{\circ} \mathrm{C}$ above (or below) the threshold temperature.

Setting Brisbane, Australia.

Patients 22805 cardiovascular deaths registered between 1996 and 2004

Main outcome measures Deaths from cardiovascular diseases.

Results The results show a longer lagged effect in cold days and a shorter lagged effect in hot days. For the hot effect, a statistically significant association was observed only for lag 0-1 days. The percentage increase in mortality was found to be $3.7 \%(95 \% \mathrm{Cl} 0.4 \%$ to $7.1 \%)$ for people aged $\geq 65$ years and $3.5 \%$ (95\% $\mathrm{Cl} 0.4 \%$ to $6.7 \%$ ) for all ages associated with an increase of $1^{\circ} \mathrm{C}$ above the threshold temperature of $24^{\circ} \mathrm{C}$. For the cold effect, a significant effect of temperature was found for 10-15 lag days. The percentage estimates for older people and all ages were $3.1 \%(95 \% \mathrm{Cl} 0.7 \%$ to $5.7 \%)$ and $2.8 \%(95 \%$ $\mathrm{Cl} 0.5 \%$ to $5.1 \%)$, respectively, with a decrease of $1^{\circ} \mathrm{C}$ below the threshold temperature of $24^{\circ} \mathrm{C}$.

Conclusions The lagged effects lasted longer for cold temperatures but were apparently shorter for hot temperatures. There was no substantial difference in the lag effect of temperature on mortality between all ages and those aged $\geq 65$ years in Brisbane, Australia.

The association between temperature and cardiovascular deaths (CVD) has long been known. ${ }^{1}$ There is an increasing interest in the assessment of this relationship as a response to climate change resulting from increased emissions of anthropogenic greenhouse gases. $^{2} 3$

There is a broad agreement that the relationship between temperature and CVD is V-, U- or J-shaped, with the optimum temperature corresponding to the lowest point in the temperature-mortality curve. ${ }^{4}$ Investigators divide temperature into three linear parts with hot and cold thresholds. The middle section is constrained to a zero slope and the $\mathrm{V}$-shaped association is the special case when cold and hot thresholds are equal. ${ }^{6}$

A lagged effect of temperature on mortality is well known. ${ }^{7}$ The mortality of the current day may be associated with exposure to the temperatures of the current day and of several previous days. ${ }^{8} 9$ Recently, a distributed lag model has been applied to explore the lag structure of temperature on mortality. Because there is substantial correlation between temperatures on days close together, investigators have implemented constrained distributed lag models (CDLM) including stratified, polynomial and smoothing CDLM to overcome this problem. ${ }^{6}$ In addition, CDLM could specify some assumptions on the shape of the distributed lagged effect and provide more precise estimates for individual lag day. ${ }^{10} 11$

The impact of temperature on mortality varies with population because local geographical conditions (ie, vegetation) and adaptation (ie, housing) are different. Although the lagged effects of temperature on CVD have been described in Europe and the USA, $^{6}{ }^{912-15}$ a recent review has pointed out that future research of allowance for the delayed temperature effects on CVD is still needed. ${ }^{15}$ However, few data are available from the Southern Hemisphere. Better understanding of these effects will provide useful information for developing public health intervention programmes and risk management that will better target those most vulnerable to temperature-related CVD

This study identified the lagged effects of mean temperature on CVD for all ages and those aged $\geq 65$ years $\left(\mathrm{CVD}_{65+}\right)$ in Brisbane, Australia, which has a typical subtropical climate in the Southern Hemisphere.

\section{METHODS}

\section{Data collection}

The data on CVD between January 1996 and December 2004 were obtained from the Office of Economic and Statistical Research of the Queensland Treasury. The causes of cardiovascular mortality were classified according to the International Classification of Diseases 9th version (ICD-9) before December 1996 and ICD-10 between December 1996 and December 2004 (ICD-9: 390-499; ICD-10: I00-199).

Daily meteorological data including maximum temperature, minimum temperature and mean relative humidity $(\mathrm{RH})$ were obtained from the Australian Bureau of Meteorology. Mean temperature was calculated from maximum temperature and minimum temperature. Air pollution data including mean daily ozone $\left(\mathrm{O}_{3}\right)$, nitrogen dioxide $\left(\mathrm{NO}_{2}\right)$ and particulate matter with aerodynamic diameter $<10 \mu \mathrm{m}\left(\mathrm{PM}_{10}\right)$, recorded in a central monitoring site in Brisbane, were obtained from the Queensland Environmental Protection Agency.

\section{Statistical analysis}

The use of temperature indicators and thresholds was evaluated using a comparison of Akaike's 
Figure 1 Relationships between mean temperature and cardiovascular deaths (CVD) among (A) all ages and (B) those aged $\geq 65$ years in Brisbane, 1996-2004.
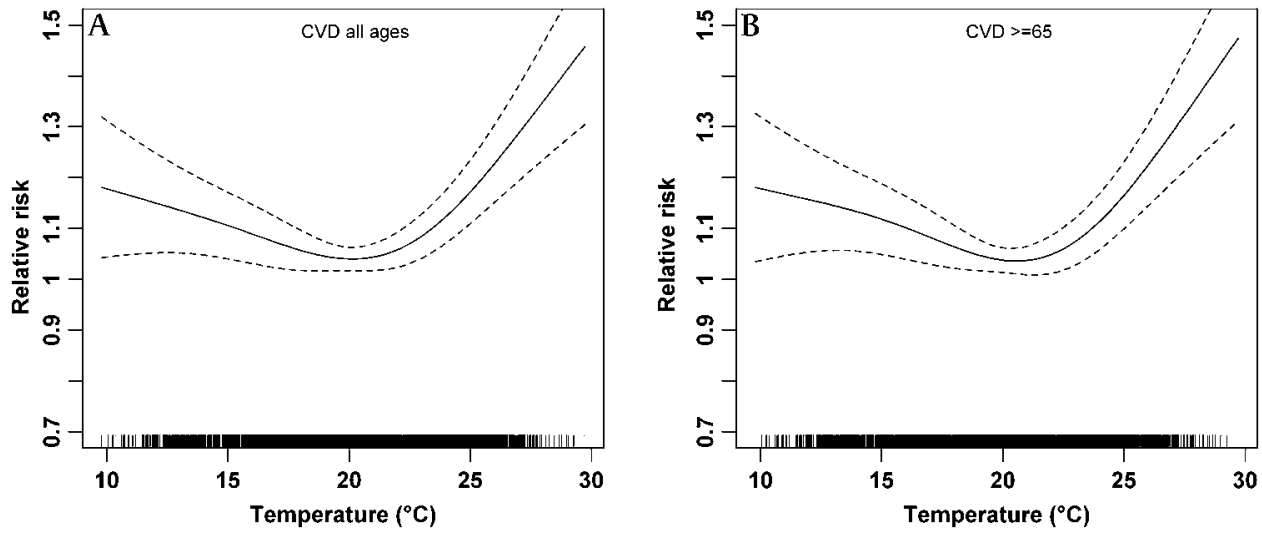

Information Criterion (AIC) for the corresponding models described in our previous study. ${ }^{16}$ Mean temperature was used as an indicator of temperature in this study because the previous study suggested that it performed better than minimum or maximum temperatures in estimates of temperature-related mortality. ${ }^{16}$

We plotted the graphs of the relationship between the current day's mean temperature and all-cause mortality based on the multivariable model with a thin plate regression splines function of temperature with 3 degrees of freedom. There was a V-shaped association between temperature and mortality as shown in figure 1. AIC values were iteratively calculated for generalised additive models using $1^{\circ} \mathrm{C}$ increments in mean temperature from $20^{\circ} \mathrm{C}$ to $30^{\circ} \mathrm{C}$, which was selected based on the visual inspection of the plots. The temperature corresponding to the model with the lowest AIC value was chosen as the threshold temperature. A similar method has been adopted in many previous studies. ${ }^{16-18}$
We applied the generalised additive model as follows: ${ }^{19}$

$$
\begin{aligned}
\log \left(Y_{t}\right) & =\alpha+\beta_{C}\left(T_{t}-\tau_{C}\right)+\beta_{H}\left(T_{t}-\tau_{H}\right) \\
& +\sum_{j=1}^{p} s\left(x_{j t}, 3\right)+\sum_{d=1}^{q} \delta_{d} x_{d}+s\left(\text { time }_{t}, 7^{*} \text { year }\right)+\varepsilon_{t}
\end{aligned}
$$

where $t$ refers to the day of the observation; $\left(Y_{t}\right)$ denotes the observed daily death counts on day $\mathrm{t} ; T_{t}$ denotes daily mean temperature on day $t ; \tau_{C}$ and $\tau_{H}$ were the cold and hot thresholds; $s($.$) denotes thin plate smoothing splines; x_{j}$ denotes the covariates of $\mathrm{RH}, \mathrm{PM}_{10}, \mathrm{NO}_{2}$ or $\mathrm{O}_{3} ; x_{d}$ represents categorical factors for day of the week, holidays and influenza outbreak; $\alpha$ is the intercept term; $\beta$ and $\delta$ are coefficients; and $\varepsilon_{\mathrm{t}}$ is the residual. Three degrees of freedom were used to smooth the covariates and the time trend was controlled by smoothing calendar time with 7 degrees of freedom/year according to previous studies. ${ }^{9} 20-23$

Polynomial distributed lag (PDL) models were used to analyse the lagged effects of mean temperature on CVD for all ages and
Figure 2 Relationships between mean temperature and cardiovascular deaths (CVD) in Brisbane, 1996-2004. (A) All ages cold; (B) all ages hot; $(C)$ those aged 65 years cold; (D) those aged $\geq 65$ years hot.
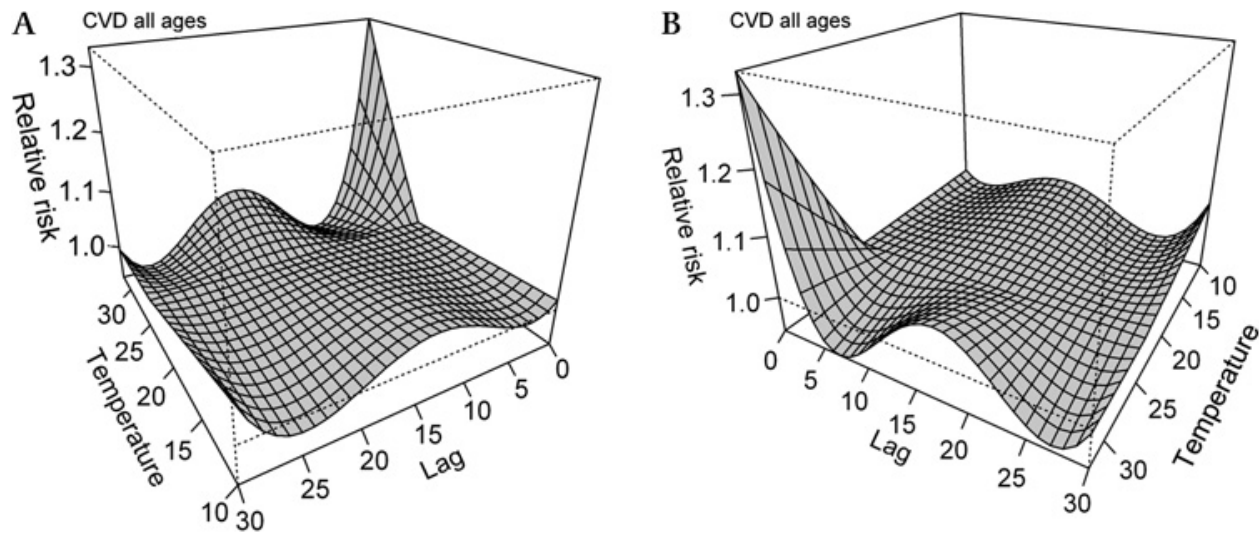

C

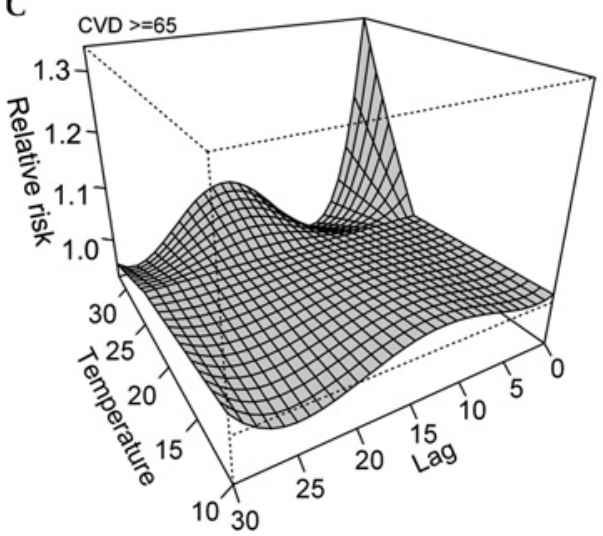

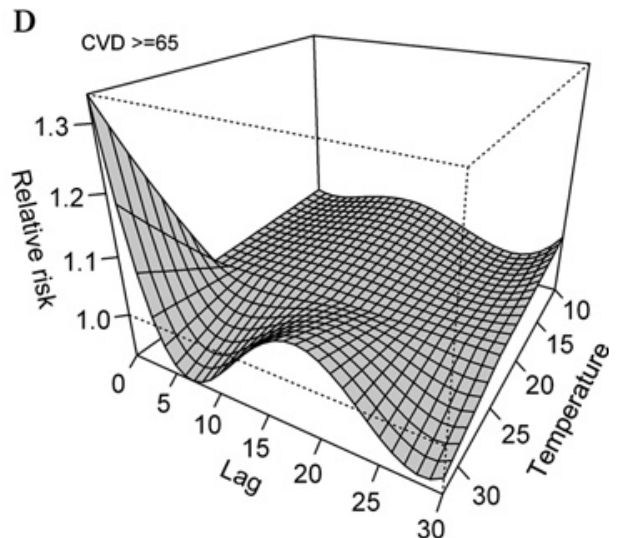



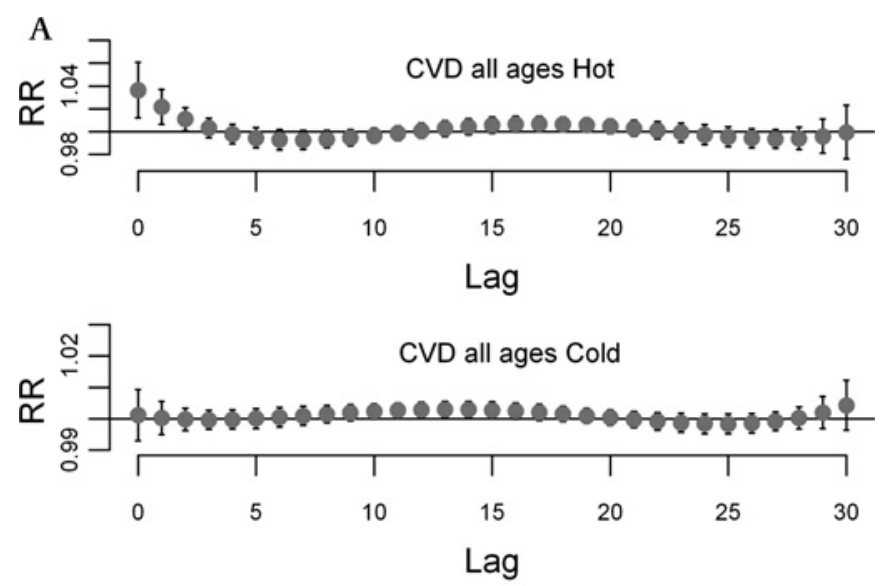

B
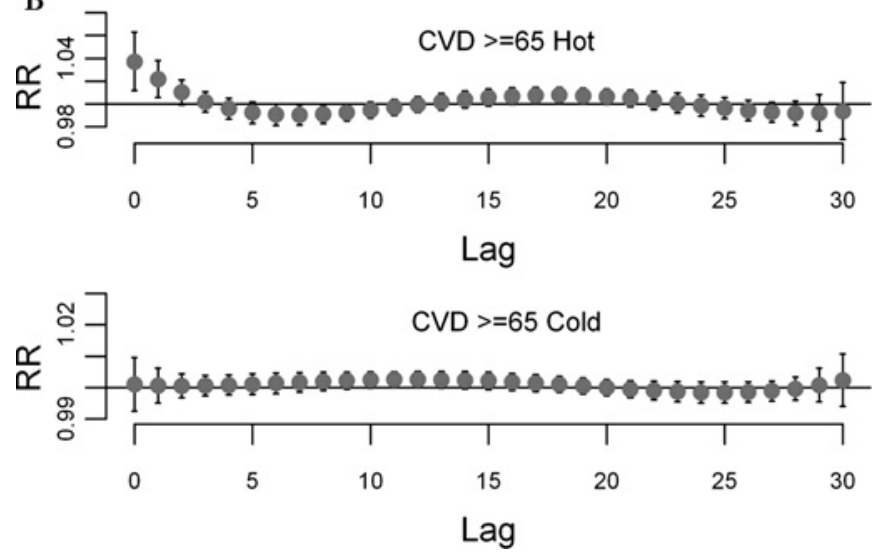

Figure 3 Relative risks of cardiovascular death (CVD) with an increase (or decrease) of $1^{\circ} \mathrm{C}$ in mean temperature among $(A)$ all ages and $(B)$ those aged $\geq 65$ years up to 30 days in Brisbane, 1996-2004.

those aged $\geq 65$ years old $\left(\mathrm{CVD}_{65+}\right)$, respectively. In order to overcome the problem of the collinearity, ${ }^{611}$ the PDL model (q,d) was implemented in equation 1 through the following restriction:

$$
\begin{gathered}
\beta_{C}\left(T_{t}-\tau_{C}\right) / \beta_{H}\left(T_{t}-\tau_{H}\right)=\alpha+\beta_{0} T_{t}+\beta_{1} T_{t-1}+\ldots \beta_{n} T_{t-\mathrm{n}} \\
\beta_{n}=\sum_{k=0}^{d} a_{k} l_{n}^{k}, l \in[0, m]
\end{gathered}
$$

where $d$ is the degree polynomial, 1 is the lags and $q$ is the maximum number of lag days. ${ }^{11}$ The fourth degree polynomial was selected as the sensitivity analyses showed no substantial changes in the results when we applied fifth or sixth order polynomials. Lags were chosen up to 30 days because longer term effects may involve longer lags. ${ }^{24}$ We used the whole dataset to plot three dimensions of lags, temperature and relative risks in the package of 'dlnm' (figure 2). ${ }^{10}{ }^{25} \mathrm{We}$ also plotted the relative risks from two angles for each age group in mortality with an increase (or decrease) of $1^{\circ} \mathrm{C}$ in the temperature above (or below) the threshold up to 30 lag days (figure 3).

Sensitivity analyses were conducted with different degrees of freedom (eg, 4, 5, 6, 8) to adjust for the long-term trends by smoothing the calendar time. Additionally, the sensitivity of including and excluding air pollutant variables was also evaluated. No substantial changes were found in these analyses. For completeness, the air pollution variables were retained in the final model.

All statistical analyses were performed in the packages of 'mgcv' and 'dlnm' in R Version 2.11.1 ( $\mathrm{R}$ Foundation for Statistical Computing, http://cran.r-project.org/).

\section{RESULTS}

The relationships between mean temperature and CVD in both age groups were observed as a V-shape (figure 1). In a total of 3274 days there were 22805 CVD registered in the study population, of which $91.4 \%$ were $\geq 65$ years of age. During the study period the average value of the mean, maximum and minimum daily temperatures and $\mathrm{RH}$ was $20.1^{\circ} \mathrm{C}, 25.2^{\circ} \mathrm{C}$, $15.4^{\circ} \mathrm{C}$ and $72.5 \%$, respectively. The mean daily average concentration of $\mathrm{PM}_{10}, \mathrm{NO}_{2}$ and $\mathrm{O}_{3}$ was $16.6 \mu \mathrm{g} / \mathrm{m}^{3}, 12.1 \mathrm{ppb}$ and $11.3 \mathrm{ppb}$, respectively (table 1 ).

The PDL model $(\mathrm{df}=4)$ showed a clear pattern of longer lagged effects in the cold temperature range and shorter lagged effects in the hot temperature range (figure 2). The highest percentage increases occurred in CVD with a lag of 10-15 days for cold and 0-1 days for heat (figure 3).

For hot effects, a $1^{\circ} \mathrm{C}$ increase in temperature above the threshold temperature was associated with overall increases of $3.5 \%(95 \%$ CI $0.4 \%$ to $6.7 \%)$ and $3.7 \%$ (95\% CI $0.4 \%$ to $7.1 \%)$ in CVD at lags $0-1$, respectively, for all ages and those aged $\geq 65$ years and $8.4 \%$ (95\% CI $1.1 \%$ to $16.2 \%)$ and $8.0 \%(95 \% \mathrm{CI}$ $0.3 \%$ to $13.2 \%$ ), respectively, at lags $0-21$ days. For cold effects, a $1{ }^{\circ} \mathrm{C}$ decrease in temperature below the threshold temperature was associated with overall increases of $2.8 \%$ (95\% CI $0.5 \%$ to $5.1 \%$ ) and $3.1 \%(95 \% \mathrm{CI} 0.7 \%$ to $5.7 \%)$ in CVD at lags $0-15$, respectively, for all ages and for those aged $\geq 65$ years (table 2 ).

\section{DISCUSSION}

To our knowledge, this is the first attempt to quantify the lagged effects of temperature on CVD in a city with a subtropical climate in the Southern Hemisphere. This study may fill a knowledge gap because the characteristics of climate,

\begin{tabular}{|c|c|c|c|c|c|c|}
\hline & \multirow[b]{2}{*}{ Mean (SD) } & \multirow[b]{2}{*}{ Minimum } & \multicolumn{3}{|c|}{ Percentile } & \multirow[b]{2}{*}{ Maximum } \\
\hline & & & $25 \%$ & $50 \%$ & $75 \%$ & \\
\hline \multicolumn{7}{|l|}{ CVD } \\
\hline All ages & $7.0(3.0)$ & 0 & 5 & 7 & 9 & 31 \\
\hline $65+$ & $6.4(2.8)$ & 0 & 4 & 6 & 8 & 31 \\
\hline \multicolumn{7}{|l|}{ Meteorological measures } \\
\hline 24-hour mean temperature $\left({ }^{\circ} \mathrm{C}\right)$ & $20.1(4.0)$ & 9.8 & 16.8 & 20.5 & 23.4 & 31.9 \\
\hline Daily relative humidity (\%) & $72.5(10.8)$ & 23.8 & 67.1 & 73.6 & 79.6 & 98.4 \\
\hline \multicolumn{7}{|l|}{ Air pollutant concentration } \\
\hline $\mathrm{PM}_{10}\left(\mu \mathrm{g} / \mathrm{m}^{3}\right)$ & $16.6(7.9)$ & 2.1 & 12.1 & 15.3 & 19.3 & 162.1 \\
\hline $\mathrm{NO}_{2}(\mathrm{ppb})$ & $12.1(5.8)$ & 2.0 & 8 & 11 & 16 & 35.8 \\
\hline $\mathrm{O}_{3}(\mathrm{ppb})$ & $11.3(4.8)$ & 0 & 8 & 11 & 14 & 45 \\
\hline
\end{tabular}

Table 1 Characteristics of mortality, weather condition and air pollutants in Brisbane, 1996-2004 
Table 2 Lagged effect of temperature on CVD among all ages and those aged $>65$ years in Brisbane, 1996-2004

\begin{tabular}{|c|c|c|}
\hline Lag days & $\begin{array}{l}\text { Hot effects }\left(\geq 24^{\circ} \mathrm{C}\right) \\
\text { Overall } \% \text { increase } \dagger(95 \% \mathrm{CI})\end{array}$ & $\begin{array}{l}\text { Cold effects }\left(<24^{\circ} \mathrm{C}\right) \\
\text { Overall \% increase } \neq(95 \% \mathrm{Cl})\end{array}$ \\
\hline \multicolumn{3}{|l|}{ All CVD } \\
\hline $0-1$ & $3.5(0.4 \text { to } 6.7)^{*}$ & $0.1(-1.0$ to 1.2$)$ \\
\hline $0-7$ & $3.0(-1.8$ to 8.1$)$ & $0.6(-1.2$ to 2.4$)$ \\
\hline $0-15$ & $4.5(-1.7$ to 11.0$)$ & $2.8(0.5 \text { to } 5.1)^{*}$ \\
\hline $0-21$ & $8.4(1.1 \text { to } 16.2)^{*}$ & $3.2(0.6 \text { to } 5.9)^{*}$ \\
\hline $0-30$ & $7.4(-0.6$ to 15.9$)$ & $3.4(0.6 \text { to } 6.3)^{*}$ \\
\hline \multicolumn{3}{|l|}{$\mathrm{CVD}_{65+}$} \\
\hline $0-1$ & $3.7(0.4 \text { to } 7.1)^{*}$ & $0.1(-1.0$ to 1.2$)$ \\
\hline $0-7$ & $2.5(-2.7$ to 7.8$)$ & $1.0(-0.8$ to 3.0$)$ \\
\hline $0-15$ & $3.3(-3.1$ to 10.2$)$ & $3.1(0.7 \text { to } 5.7)^{*}$ \\
\hline $0-21$ & $8.0(0.3 \text { to } 13.2)^{*}$ & $3.2(0.4 \text { to } 6.2)^{*}$ \\
\hline $0-30$ & $6.0(-2.3$ to 15.0$)$ & $3.2(0.1 \text { to } 6.5)^{*}$ \\
\hline
\end{tabular}

adaptation and sociodemographic patterns in Brisbane are likely to differ from cities in Europe or the USA. We investigated lagged effects up to 30 days on all for both cold and hot effects. A delayed effect of approximately 2 weeks was observed for cold temperatures, but the apparent hot effects were identified at lags $0-1$ days.

Several hypotheses have been proposed to explain the mechanism of the association between temperature and cardiovascular mortality. Environmental temperature has an inverse relation with blood pressure. ${ }^{26}$ Cold temperature may exert a direct effect on the heart or have an indirect effect via changes in blood pressure. ${ }^{27}$ An increase in plasma cholesterol and plasma fibrinogen with cold temperatures, coupled with a higher blood pressure, could lead to thrombosis through haemoconcentration and trigger an acute cardiac event. ${ }^{13} 2829$ In hot weather the heat balance of the body is sustained by enlarging skin vessels and increased sweating which in turn increases the cardiac work and loss of fluid and salt. This may lead to haemoconcentration, increased blood viscosity and the risk of thrombosis. $^{30} 31$

In addition, the different types of CVD may have different sensitivity to higher and lower temperatures. For example, cold temperature can induce deaths from myocardial ischaemia and acute myocardial infarction ${ }^{32} 33$ while, in people with congestive heart failure, the extra heat load may lead to fatal consequences. $^{30} 31$

In this study the strongest effects of heat were found shortly after exposure in both age groups. This is in agreement with results from earlier heat-related mortality studies which identified temperature-related CVD from recent exposure (ie, same day and a few days previously) in Europe and the USA. ${ }^{4} 83435$ Heat seems to induce an acute event in CVD for advanced forms of illness (eg, myocardial infarction and stroke) among people who may be expected to die within a short period. ${ }^{36}$ On the other hand, cold-related mortality did not occur immediately but was observed after approximately 1 week, persisting for approximately 2 weeks in both groups. Other researchers reported similar findings. ${ }^{24} 37-39$

These results show that the relationship between temperature and mortality is similar among all ages and those aged $\geq 65$ years. Other studies have also found that the effect of temperature on CVD did not vary with age. ${ }^{13} 40$ Although the ability of older adults to maintain the core temperature is usually compromised, other factors such as living conditions (including being equipped with air conditioning), family and/or social cares as well as medical support can modify the effect of temperature on mortality in elderly people. ${ }^{41}$ One possible explanation for this finding is that members of the susceptible group of $\mathrm{CVD}_{65+}$ modify their behavioural patterns in cold or hot weather (ie, spending less time outdoors or using air conditioning). ${ }^{13}$ Another explanation is that the majority of CVD in Brisbane (91.4\%) is experienced by people aged $\geq 65$ years.

It has long been known that there is an association between air pollution and increased CVD in different parts of the world. ${ }^{42}$ Pollution exposure leads to disturbances in the autonomic control of the heart, reflecting altered balance of the sympathetic and parasympathetic nervous systems. ${ }^{43}$ Ambient temperature and air pollution levels often influence human health on a daily basis. Thus, the actual association between ambient temperature and mortality should be assessed after adjustment for air pollutants in the models. ${ }^{44}$

This study has three major strengths. First, to our knowledge this is the first research on the lag structure of temperature on CVD in a city in the Southern Hemisphere. Second, this study examined both cold and hot lagged effects on mortality up to 30 days for people of all ages and for elderly people. Third, the PDL model was applied to overcome the collinearity of the temperatures on days close together. The sensitivity analyses were used to evaluate the outputs of the PDL model with different degrees polynomial.

This study also has two limitations. First, although we found that hot temperature effects were acute but cold temperature effects lasted longer, the specific lag structures used here were intended to be representative, not to reflect the exact lag measurements appropriate for the relationship between temperature and mortality. Second, we only focused on one city and therefore the results of this study have limited generalisability.

These findings on the lag structure of temperature on CVD may have implications for policy-making. The identified lags signify the need for targeted efforts to prevent the effects of temperature on mortality. Results on lags for different subpopulations are particularly important for estimating temperaturerelated mortality from climate change.

\section{CONCLUSIONS}

The lagged effects of temperature on CVD lasted longer during cold days but were shorter during hot days. The cardiovascular vulnerability to temperature stress was similar for all ages and for those aged $\geq 65$ years.

Acknowledgements We thank Dr Cizao Ren for his statistical advice and the Office of Economic and Statistical Research of the Queensland Treasury, Australian Bureau of Meteorology and the Queensland Environmental Protection Agency for providing the relevant data.

Funding This work was partly supported by an Australian Research Council Discovery grant (\#559655). ST was supported by an NHMRC Research Fellowship (\#553043) and WY was supported by a Queensland University of Technology scholarship.

Competing interests None.

Ethics approval This study was conducted with the approval of the Queensland University of Technology ethical committee.

Provenance and peer review Not commissioned; externally peer reviewed.

\section{REFERENCES}

1. Anderson TW, Le Riche WH. Cold weather and myocardial infarction. Lancet 1970;1:291-6.

2. Schwartz J. The effects of particulate air pollution on daily deaths: a multi-city case crossover analysis. Occup Environ Med 2004;61:956-61. 
3. Henrotin JB, Zeller M, Lorgis L, et al. Evidence of the role of short-term exposure to ozone on ischaemic cerebral and cardiac events: the Dijon Vascular Project (DIVA). Heart 2010;96:1990-6.

4. Curriero FC, Heiner KS, Samet JM, et al. Temperature and mortality in 11 cities of the eastern United States. Am J Epidemiol 2002;155:80-7.

5. Kassomenos P, Gryparis A, Samoli E, et al. Atmospheric circulation types and daily mortality in Athens, Greece. Environ Health Perspect 2001;109:591-6.

6. Armstrong B. Models for the relationship between ambient temperature and daily mortality. Epidemiology 2006;17:624-31.

7. Rogot E, Blackwelder WC. Associations of cardiovascular mortality with weather in Memphis, Tennessee. Public Health Rep 1970;85:25-39.

8. Bi P, Parton KA, Wang J, et al. Temperature and direct effects on population health in Brisbane, 1986-1995. J Environ Health 2008;70:48-53.

9. Anderson BG, Bell ML. Weather-related mortality: how heat, cold, and heat waves affect mortality in the United States. Epidemiology 2009;20:205-13.

10. Gasparrini A, Armstrong B. Time series analysis on the health effects of temperature: advancements and limitations. Environ Res 2010;110:633-8.

11. Schwartz J. The distributed lag between air pollution and daily deaths. Epidemiology 2000;11:320-6.

12. Hajat S, Armstrong BG, Gouveia N et al. Mortality displacement of heat-related deaths: a comparison of Delhi, Sao Paulo, and London. Epidemiology 2005; 16:613-20.

13. Carder M, McNamee R, Beverland I, et al. The lagged effect of cold temperature and wind chill on cardiorespiratory mortality in Scotland. Occup Environ Med 2005;62:702-10.

14. Braga AL, Zanobetti A, Schwartz J. The time course of weather- related deaths. Epidemiology 2001;12:662-7.

15. Bhaskaran K, Hajat $\mathrm{S}$, Haines $\mathrm{A}$, et al. Effects of ambient temperature on the incidence of myocardial infarction. Heart 2009;95:1760-9.

16. Yu W, Vaneckova $P$, Mengersen $K$, et al. Is the association between temperature and mortality modified by age, gender and socio-economic status? Sci Total Environ 2010;408:3513-18.

17. Chung JY, Honda $Y$, Hong $Y$ C, et al. Ambient temperature and mortality: an international study in four capital cities of East Asia. Sci Total Environ 2009;408:390-6.

18. Kim H, Ha JS, Park J. High temperature, heat index, and mortality in 6 major cities in South Korea. Arch Environ Occup Health 2006;61:265-70.

19. Dominici F, McDermott A, Hastie TJ. Improved semiparametric time series models of air pollution and mortality. J Am Stat Assoc 2004:99:938-49.

20. McMichael AJ, Wilkinson P, Kovats RS, et al. International study of temperature, heat and urban mortality: the 'ISOTHURM' project. Int $\mathrm{J}$ Epidemiol 2008:37:1121-31.

21. Hajat S, Kovats RS, Lachowycz K. Heat-related and cold-related deaths in England and Wales: who is at risk? Occup Environ Med 2007:64:93-100.

22. Stafoggia M, Schwartz J, Forastiere F, et al. Does temperature modify the association between air pollution and mortality? A multicity case-crossover analysis in Italy. Am J Epidemiol 2008;167:1476-85.

23. Filleul L, Cassadou S, Medina $\mathrm{S}$, et al. The relation between temperature, ozone, and mortality in nine French cities during the heat wave of 2003. Environ Health Perspect 2006:114:1344-7.
24. Pattenden S, Nikiforov B, Armstrong BG. Mortality and temperature in Sofia and London. J Epidemiol Community Health 2003;57:628-33.

25. Gasparrini A, Armstrong B, Kenward MG. Distributed lag non-linear models. Stat Med 2010;29:2224-34

26. Kunes J, Tremblay J, Bellavance F, et al. Influence of environmental temperature on the blood pressure of hypertensive patients in Montréal. Am J Hypertens 1991:4:422-6.

27. Pell JP, Cobbe SM. Seasonal variations in coronary heart disease. OJM 1999:92:689-96

28. Medina-Ramón M, Schwartz J. Temperature, temperature extremes, and mortality: a study of acclimatisation and effect modification in 50 United States cities. Occup Environ Med 2007:64:827-33

29. Ballester F, Corella D, Perez-Hoyos $S$, et al. Mortality as a function of temperature a study in Valencia, Spain, 1991-1993. Int J Epidemiol 1997;26:551-61.

30. Keatinge WR, Coleshaw SR, Easton JC, et al. Increased platelet and red cell counts, blood viscosity, and plasma cholesterol levels during heat stress, and mortality from coronary and cerebral thrombosis. Am J Med 1986;81:795-800.

31. Näyhä S. Environmental temperature and mortality. Int J Circumpolar Health 2005;64:451-8.

32. Hong YC, Rha JH, Lee JT, et al. Ischemic stroke associated with decrease in temperature. Epidemiology 2003;14:473-8.

33. Stewart S, Mclntyre K, Capewell S, et al. Heart failure in a cold climate: seasonal variation in heart failure-related morbidity and mortality. J Am Coll Cardiol 2002;39:760-6.

34. Baccini M, Biggeri A, Accetta G, et al. Heat effects on mortality in 15 European cities. Epidemiology 2008;19:711-19.

35. Analitis A, Katsouyanni K, Biggeri A, et al. Effects of cold weather on mortality: results from 15 European cities within the PHEWE project. Am J Epidemiol 2008;168:1397-408.

36. Muggeo VM, Hajat S. Modelling the non-linear multiple-lag effects of ambient temperature on mortality in Santiago and Palermo: a constrained segmented distributed lag approach. Occup Environ Med 2009;66:584-91.

37. Goodman PG, Dockery DW, Clancy L. Cause-specific mortality and the extended effects of particulate pollution and temperature exposure. Environ Health Perspect 2004;112:179-85.

38. Gouveia $\mathbf{N}$, Hajat $\mathrm{S}$, Armstrong B. Socioeconomic differentials in the temperature-mortality relationship in Sao Paulo, Brazil. Int J Epidemio 2003:32:390-7.

39. Braga AL, Zanobetti A, Schwartz J. The effect of weather on respiratory and cardiovascular deaths in 12 US cities. Environ Health Perspect 2002;110:859-63.

40. Revich B, Shaposhnikov D. Temperature-induced excess mortality in Moscow, Russia. Int J Biometeorol 2008;52:367-74.

41. Stafoggia M, Forastiere F, Agostini D, et al. Factors affecting in-hospital heat-related mortality: a multi-city case-crossover analysis. J Epidemiol Community Health 2008:62:209-15

42. Boyd JT. Climate, air pollution, and mortality. Br J Prev Soc Med 1960;14:123-35

43. Bhaskaran $\mathbf{K}$, Hajat S, Haines $A$, et al. Effects of air pollution on the incidence of myocardial infarction. Heart 2009:95:1746-59.

44. Basu R. High ambient temperature and mortality: a review of epidemiologic studies from 2001 to 2008. Environ Health 2009:8:40-52.

Visit Heart online for free editor's choice articles, online archive, email alerts, blogs or to submit your paper. Keep informed and up to date by registering for electronic table of contents at heart.bmj.com. 


\section{HEART}

\section{Time course of temperature effects on cardiovascular mortality in Brisbane, Australia}

Weiwei Yu, Wenbiao Hu, Kerrie Mengersen, et al.

Heart 2011 97: 1089-1093 originally published online April 12, 2011 doi: 10.1136/hrt.2010.217166

Updated information and services can be found at:

http://heart.bmj.com/content/97/13/1089.full.html

These include:

References This article cites 44 articles, 18 of which can be accessed free at: http://heart.bmj.com/content/97/13/1089.full.html\#ref-list-1

Email alerting Receive free email alerts when new articles cite this article. Sign up in service the box at the top right corner of the online article.

Topic Articles on similar topics can be found in the following collections Collections

Notes

To request permissions go to:

http://group.bmj.com/group/rights-licensing/permissions

To order reprints go to:

http://journals.bmj.com/cgi/reprintform

To subscribe to BMJ go to:

http://group.bmj.com/subscribe/ 